\title{
Article \\ Injury Incidence and Pattern in Elite Young Male and Female Trail Runners
}

\author{
Luis F. Sanchez-Garcia $(\mathbb{D}$, Alfonso Penichet-Tomas $(\mathbb{D}$, Basilio Pueo *(i) and Jose M. Jimenez-Olmedo
}

check for

updates

Citation: Sanchez-Garcia, L.F.;

Penichet-Tomas, A.; Pueo, B.; Jimenez-Olmedo, J.M. Injury Incidence and Pattern in Elite Young Male and Female Trail Runners. Appl. Sci. 2022, 12, 1155. https://doi.org/ 10.3390/app12031155

Academic Editors: Enrique Navarro, Santiago Veiga and Alejandro San Juan Ferrer

Received: 13 December 2021

Accepted: 20 January 2022

Published: 22 January 2022

Publisher's Note: MDPI stays neutral with regard to jurisdictional claims in published maps and institutional affiliations.

Copyright: (c) 2022 by the authors. Licensee MDPI, Basel, Switzerland. This article is an open access article distributed under the terms and conditions of the Creative Commons Attribution (CC BY) license (https:// creativecommons.org/licenses/by/ $4.0 /)$.
Research Group in Health, Physical Activity, and Sports Technology (Health-Tech), Faculty of Education, University of Alicante, 03690 San Vicente del Raspeig, Spain; lf.sanchez@ua.es (L.F.S.-G.); alfonso.penichet@ua.es (A.P.-T.); j.olmedo@ua.es (J.M.J.-O.)

* Correspondence: basilio@ua.es

\begin{abstract}
The aim of this study was to analyze the injury incidence in young trail runners according to the body region, type, mode of onset, and moment of occurrence, both in total and detailed by sex. Thirty-five male and sixteen female young elite trail runners, aged between 15 and 22 years, completed a questionnaire regarding the injury incidence in the last 2 years. Comparison of the proportions of the injury incidence within groups (all, male, and female runners) and between groups (male vs. female runners) was computed using $z$ and Fisher's exact tests. Results showed that most of the injuries in male runners occurred in ankle $(54.3 \% ; p<0.001 ; \mathrm{ES}=0.520)$. New injuries were the most common type in male $(60.0 \% ; p<0.001 ; \mathrm{ES}=0.829)$ and female runners $(52.0 \% ; p=0.005$; $\mathrm{ES}=0.585)$. Acute sudden onset $(55.7 \% ; p=0.002 ; \mathrm{ES}=0.722)$ and repetitive sudden onset injuries $(48.0 \% ; p=0.002 ; \mathrm{ES}=0.141)$ were the most frequent in male and female athletes, respectively. Joint sprains $(48.6 \% ; p<0.001 ; 0.464)$ were the most reported injuries in male runners. Comparative analysis between sexes showed that exacerbation injuries were higher in females (24.0\%) than in male runners $(8.6 \%)$, with $p=0.046(\mathrm{ES}=0.205)$. However, female runners reported less incidence by acute sudden onset injuries $(32.0 \%)$ than male runners $(55.7 \%)$, with $p=0.042(\mathrm{ES}=0.209)$. Young trail runners showed a specific injury profile due to the distinctive characteristics of the mountain terrain compared to the athletic modalities.
\end{abstract}

Keywords: race; mountain; endurance; joint sprain; tendinopathy; ankle; repetitive gradual onset

\section{Introduction}

Running is a popular and convenient physical activity that shows a significant positive impact on longevity [1]. It also affects the perception of health and wellness of practitioners [2]. Studies have demonstrated that natural public spaces allow people to escape from their daily routines and stressful environments, and help them to revitalize [3,4]. As a consequence, trail running has been developed a lot in recent years in terms of the number of events and participation $[5,6]$. This rise in practice has also led to an increase in terms of research on this sport, mainly related to ultra-distance, either in terms of fatigue reduction, muscle development, or other aspects of this discipline [7-10]. Several studies have confirmed the benefits of running, but also a high injury risk [11-13], defined as tissue damage or other derangement of normal physical function due to participation in sports, resulting from the rapid or repetitive transfer of kinetic energy [14]. In the case of trail running, the combination of high mileage, together with changing terrain and large uphill and downhill slopes forces the athlete to a continuous change in terms of technique and fatigue management [15]. These characteristics have led many authors to generally accept that mountain races, and more specifically ultra-distance races, induce serious and harmful alterations in the neuromuscular [16], energetic [17], biomechanical [18], and musculoskeletal oxygenation fields [19].

Long-duration races are characterized by high impact loads induced by extreme conditions in terms of duration, weather, and gradient, especially during the descent. In 
this type of race, Morin et al. [18] observed changes towards higher oscillation frequency, reduced flight time, and reduced vertical oscillation in order to acquire a safer running pattern. However, Gianluca et al. [20] concluded that a conscious change in the tread pattern did not demonstrate a reduction in muscle fatigue, a good running technique being more important, as occurs in other running sports [21,22].

Running on slopes with a negative gradient could increase the injury risk as well as an additional effort for the musculoskeletal tissue as a product of greater length between the center of gravity and the point of support and its consequent peak force [23], especially in those less trained runners. On the other hand, the continuous change of the movement pattern caused by downhill reduces the number of repetitive gradual onset injuries related to the repetition of movements because, as mentioned above, the variation of the terrain modifies the support pattern continuously, lengthening or shortening the stride and adapting the footprint to the characteristics of the ground. This results in the non-repetition of a footprint pattern [15] unlike what happens in races on flat terrain and without abrupt changes in elevation (either asphalt or tartan).

Despite these biomechanical alterations to achieve safer patterns, the continuous increase in the number of runners, as well as the characteristics of this sport, have led to the appearance of various pathologies. A recent review carried out by Viljoen, Janse van Rensburg, et al. [24] concluded that the most injured region in trail runners was the foot, followed by the knee, lower leg, thigh, and ankle. Vernillo et al. [25] analyzed 70 ultra-trail runners and concluded that the rate of injury and/or illness was 13.1 per $1000 \mathrm{~h}$ of training, highlighting ankle sprains (suffered by $28.6 \%$ of participants), plantar fasciitis $(28.6 \%)$, and cramps $(26.2 \%)$. These data differ slightly from the study with 228 trail runners by Hespanhol, van Mechelen, and Verhagen [26], indicating that the injury rate was 10.7 per $1000 \mathrm{~h}$ and that the most common injuries were Achilles tendon (12.8\%), calf muscle $(10.7 \%)$, undiagnosed knee pain (8.7\%), and an ankle sprain (7.0\%). It seems that sex is also a factor to consider. It was found that there are differences in risk taking between male and female runners [27], being males more prone to sports accidents. However, not only that but there are also sex differences in the type of predominant injuries in male and female ultra-runners [28].

These investigations are useful to analyze the current issue, hypothesize about the possible causes and develop interventions for their prevention [29]. Most of the studies referred to runners of distances longer than the marathon. However, to the knowledge of the authors, very few studies have been conducted with trail runners in shorter distances, among which none is devoted to the analysis of young trail runners.

Therefore, the present study aims to determine which body regions have suffered the most injuries in young trail runners and classify them according to the type, mode of onset, and moment of occurrence, analyzed by sex. Our hypothesis was that most were in the lower part of the body, with the ankles and knees being the most affected areas. We also hypothesized that there were differences between sexes in the type of lesions and the region of the body affected. This information can be useful to adapt both physical preparation and prevention programs, aiming at reducing the number of injuries, avoiding the appearance of chronic pain, and facilitating a steady progression in these young runners towards high sports competition.

\section{Materials and Methods}

\subsection{Participants}

Fifty-one young trail runners called upon to represent Spain in international competitions, aged between 15 and 22 years, participated in the study ( 35 males, height: $173.2 \pm 6.1 \mathrm{~cm}$, body mass: $63.2 \pm 6.7 \mathrm{~kg}$, and 16 females, height $160.5 \pm 4.7 \mathrm{~cm}$, body mass $55.5 \pm 3.6 \mathrm{~kg}$ ). All subjects signed a written informed consent before participation, including written parental consent for trail runners aged $<18$ years old. The study protocol was conducted according to the guidelines of the Declaration of Helsinki and was approved by the Ethics Committee of the University of Alicante (UA 2019-02-25). 


\subsection{Procedures}

An adapted Spanish language questionnaire [30], based on the validated questionnaire by Eloranta and Tittonen [31] was used. The participants completed the questionnaire regarding the injuries caused while practicing trail running in the last 2 years. Based on the time that each participant dedicated to the practice of trail running and the number of occurrences, the incidence of injuries per $1000 \mathrm{~h}$ for each athlete was calculated [32]:

$$
\text { Injury incidence }=(\text { number of injuries } \times 1000) / \text { practice hours }
$$

The participants also indicated the body region of each injury: arm, hip, elbow, spine, neck, fingers, hand, toes, shoulder, intercostal, hamstring, wrist, thigh, nose, foot, lower leg, ankle, or non-specific region, together with the body size of occurrence. This information was later aggregated into body regions for analysis: lower extremities, upper extremities, trunk, or head. Furthermore, according to the International Olympic Committee Consensus Statement [14], information about the moment was retrieved: directly related injuries (differentiated between training and competition), indirectly injuries and injuries not at all related to participation in sports. Finally, type (new, recurrent, or exacerbation injury), mode of onset (acute sudden onset, repetitive sudden onset, or repetitive gradual onset), and time loss of each injury was also retrieved. The definitions of the above injuries are as follows [14]:

- $\quad$ Acute sudden onset: caused by the impact of a body surface against an external agent.

- $\quad$ Repetitive sudden onset: the athlete can specify the action and the exact moment it occurred.

- $\quad$ Repetitive gradual onset: the triggering moment cannot be identified, but not as a chronic injury.

\subsection{Statistical Analysis}

Statistical analysis was performed using the Statistical Package for Social Sciences (SPSS V26.0 for Windows, IBM Corp., Armonk, NY, USA). Descriptive analysis was used to obtain the frequencies and percentages of all the variables. The $z$-test was computed for the comparison and contrast of proportions of injury incidence within groups (in total, male, and female runners), using Cramer's $V$ to calculate effect sizes (ES $\leq 0.2=$ weak; $0.2<\mathrm{ES} \leq 0.6=$ moderate; $\mathrm{ES}<0.6=$ strong) [33]. Additionally, for the comparison between groups (male vs. female runners), effect sizes were calculated using Phi (ES $\leq 0.1=$ small; $0.1<$ ES $\leq 0.3$ = medium; ES $<0.5=$ large) $[33,34]$. The standard normal distribution of the $z$-value was calculated to obtain the $p$-value of the $z$-test. In cases where the expected frequency count was less than 5 , the Fischer exact test was performed instead of the $z$-test. The statistical significance was set at $p<0.05$.

\section{Results}

The descriptive analysis of the training time shows that the mean weekly hours dedicated to training is $8.7 \pm 2.4 \mathrm{~h}$, in which $68.6 \%$ of the surveyed athletes dedicate between 6 and $10 \mathrm{~h} /$ week to training. The results of these data disaggregated by sex showed a similar load: $8.8 \pm 2.4 \mathrm{~h} /$ week in male and $8.6 \pm 2.3 \mathrm{~h} /$ week in female athletes.

Globally, results showed that 6 athletes out of 51 (2 male and 4 female trail runners) did not report any injury, which indicates an incidence of $88.2 \%$. Among these, athletes reporting 1 or 2 occurrences predominated (33.3\% and $29.4 \%$ respectively). The remaining 45 athletes accounted for a total of 95 injuries. The analysis of practice hours indicated $2.2 \pm 1.8$ injuries per $1000 \mathrm{~h}$ of practice hours. The results also showed that most occurred in the following regions: ankles $(49.5 \%)$, knees $(17.9 \%)$, and lower legs $(9.5 \%)$, as shown in Table 1 . The $z$ test showed significant differences between ankle injuries compared to the rest of the regions $(p<0.001 ; \mathrm{ES}=0.462)$. 
Table 1. Body region of injuries in male and female trail runners.

\begin{tabular}{|c|c|c|c|c|c|c|c|c|}
\hline & \multicolumn{2}{|c|}{$\begin{array}{c}\text { All } \\
(n=95)\end{array}$} & \multicolumn{2}{|c|}{$\begin{array}{c}\text { Male } \\
(n=70)\end{array}$} & \multicolumn{2}{|c|}{$\begin{array}{l}\text { Female } \\
(n=25)\end{array}$} & \multirow[t]{2}{*}{$p$} & \multirow{2}{*}{ ES $(\varphi)$} \\
\hline & $\%$ & $(n)$ & $\%$ & $(n)$ & $\%$ & $(n)$ & & \\
\hline Ankle & $49.5 \#$ & (47) & $54.3 \#$ & (38) & 36.0 & $(9)$ & 0.116 & 0.161 \\
\hline Knee & 17.9 & (17) & 18.6 & (13) & 16.0 & $(4)$ & 1.000 & 0.030 \\
\hline Lower leg & 9.5 & (9) & 5.7 & (4) & 20.0 & (5) & 0.051 & 0.215 \\
\hline Thigh & 5.3 & (5) & 4.3 & (3) & 8.0 & $(2)$ & 0.604 & 0.073 \\
\hline Wrist & 4.2 & $(4)$ & 4.3 & (3) & 4.0 & $(1)$ & 1.000 & 0.006 \\
\hline Toes & 4.2 & (4) & 1.4 & (1) & 12.0 & (3) & 0.055 & 0.232 \\
\hline Foot & 3.2 & (3) & 4.3 & (3) & 0.0 & $(0)$ & 0.564 & 0.108 \\
\hline Shoulders & 2.1 & $(2)$ & 2.9 & $(2)$ & 0.0 & $(0)$ & 1.000 & 0.088 \\
\hline Elbow & 1.1 & $(1)$ & 1.4 & (1) & 0.0 & $(0)$ & 1.000 & 0.062 \\
\hline Nails & 1.1 & $(1)$ & 1.4 & $(1)$ & 0.0 & $(0)$ & 1.000 & 0.062 \\
\hline Non-specific & 2.1 & $(2)$ & 1.4 & (1) & 4.0 & $(1)$ & 0.459 & 0.079 \\
\hline
\end{tabular}

\# Significant differences between body regions $(p<0.05)$.

The analysis by sex shows that the number of reported athletes injured was greater for males (33 out of $35 ; 94.3 \%$ ) than for female runners (12 out of $16 ; 75.0 \%$ ). In regards to the incidence by training hours, male runners reported $2.3 \pm 1.9$ injuries every $1000 \mathrm{~h}$, compared to $1.8 \pm 1.3$ in female runners. The body regions with greater prevalence in male athletes were ankle $(54.3 \%)$, significantly larger than the rest of body regions $(p<0.001$; $\mathrm{ES}=0.520)$. In female athletes, the ankle remains the most affected region $(36 \%)$, followed by the lower leg $(20 \%)$ and the knee $(16 \%)$. However, no significant differences were observed between any regions, so percentages were more distributed in female runners. Comparing between sexes, no significant differences were observed.

The analysis according to the moment of occurrence showed that trail runners got injured most during training and competitions ( $40.0 \%$ and $33.7 \%$, respectively), as shown in Table 2. The remaining activities were indirect injuries (2.1\%), and not at all related to trail running, accounting for $24.2 \%$ of the total. The results segmented by sex showed very similar percentages. In regards to the body region most affected, all injuries to the toes were directly related injuries and occurred in competition, whereas $52.9 \%$ of knee injuries occurred in training versus $11.8 \%$ produced in competition. In the case of ankle injuries, $40.4 \%$ occurred in competition, and $42.6 \%$ occurred during training.

Regarding the type of injury, $57.0 \%$ were new $(p<0.001$; ES $=0.758), 29.5 \%$ recurrent $(p=0.016$; ES $=0.016)$ and $12.5 \%$ exacerbation injuries, with significant differences among them. While this trend is similar in male athletes, with significant differences in new injuries $(p<0.001$; ES $=0.829)$, the percentages of recurrent and exacerbation injuries in female athletes are both $24.0 \%$, with new injuries being only significantly higher $(52.0 \%, p=0.005$; $\mathrm{ES}=0.585)$. The ankle was the body region with more new injuries $(59.8 \%)$, followed by $34.0 \%$ recurrent and $6.4 \%$ exacerbation injuries. On the other hand, of the 17 knee injuries, $64.7 \%$ were new, $17.6 \%$ recurrent, and $17.6 \%$ exacerbation injuries.

The mode of onset revealed that nearly half of the injuries reported were caused by acute sudden onset $(49.5 \%)$, followed by repetitive sudden onset $(34.7 \%)$, and repetitive gradual onset $(15.8 \%)$. The $z$-test showed significant differences for acute sudden onset $(p<0.001$; ES $=0.722)$, and repetitive sudden onset $(p=0.001$; ES $=0.316)$. Concerning incidence by sex, most of the injuries in male runners were caused by acute sudden onset $(55.7 \%, p=<0.001$; ES = 0.734), followed by repetitive sudden onset $(30.0 \%, p=0.027$; $\mathrm{ES}=0.267)$ and repetitive gradual onset $(14.3 \%)$. Contrastingly, female runners reported less incidence by acute sudden onset than male runners $(32.0 \% ; p=0.042$; ES $=0.209)$, so that repetitive sudden onset was the most common injury in female runners $(48 \%, p=0.039$; ES $=0.480$ ), followed by repetitive gradual onset $(20.0 \%)$. The analysis of the mode of onset in each body region revealed that the number of ankle injuries is higher due to acute sudden onset $(55.3 \%)$ compared to repetitive sudden onset $(23.4 \%)$ and repetitive gradual 
onset $(21.3 \%)$. However, knee injuries were originated from repetitive sudden onset $(58.8 \%)$, rather than from repetitive gradual onset $(23.5 \%)$ or from acute sudden onset $(17.6 \%)$.

The highest incidence occurred in the right side of the body (60\%), compared to $40 \%$ on the left side $(p<0.001$; ES $=1.000)$. With regards to sex, most of the injuries in male runners were reported on the right side $(62.9 \%)$, compared to the left side $(37.1 \%)$, which difference was significant $(p<0.001 ; E S=1.000)$. However, the incidence in female runners was balanced between right (52\%) and left sides (48.0\%). According to body segments in body sides, similar differences were observed in lower legs (77.8\% vs. $22.2 \%$ left) and in the knee (70.6\% right vs. $29.4 \%$ left). In the case of the ankle, although both sides showed dissimilar incidence (59.6\% right vs. $40.4 \%$ left).

The time most runners were inactive due to injuries was between $8-21$ days (32.6\%), followed by more than 21 days (24.2\%) and 4-7 days (17.9\%). According to differences by sex, male runners showed higher percentages in all periods longer than 4 days than female runners, meaning that the former needs more time for recovery. As for the absence of recovery, $24 \%$ of female runners did not require recovery time compared to only $1.4 \%$ of male runners, this difference being significant $(p=0.001 ; \mathrm{ES}=0.380)$. At the other end of the scale, significant differences $(p=0.031 ; \mathrm{ES}=0.226)$ in recovery periods greater than 21 days were observed for male runners $(30.0 \%)$ compared to female runners $(8.0 \%)$. The analysis of time loss and body region highlighted that injures in the knee required more than 21 days of recovery, ankle between 8 and 21 days, and leg from 4 to 7 days.

Table 2. Characteristics of injuries in male and female trail runners.

\begin{tabular}{|c|c|c|c|c|c|c|c|c|}
\hline & \multicolumn{2}{|c|}{$\begin{array}{c}\text { All } \\
(n=95)\end{array}$} & \multicolumn{2}{|c|}{$\begin{array}{c}\text { Male } \\
(n=70)\end{array}$} & \multicolumn{2}{|c|}{$\begin{array}{l}\text { Female } \\
(n=25)\end{array}$} & \multirow{2}{*}{$p$} & \multirow{2}{*}{$\operatorname{ES}(\varphi)$} \\
\hline & $\%$ & $(n)$ & $\%$ & (n) & $\%$ & (n) & & \\
\hline \multicolumn{9}{|l|}{ Moment } \\
\hline Training & 40.0 & $(38)$ & 40.0 & $(28)$ & 40.0 & (10) & 1.000 & 0.000 \\
\hline Competition & 33.7 & (32) & 32.9 & $(23)$ & 36.0 & (9) & 0.775 & 0.029 \\
\hline Indirect injuries & 2.1 & $(2)$ & 1.4 & $(1)$ & 4.0 & (1) & 0.459 & 0.079 \\
\hline Not at all related & 24.2 & (23) & 25.7 & $(18)$ & 20.0 & (5) & 0.567 & 0.059 \\
\hline \multicolumn{9}{|l|}{ Type } \\
\hline New & $57.0 \#$ & (55) & $60.0 \#$ & $(42)$ & $52.0 \#$ & (13) & 0.487 & 0.071 \\
\hline Recurrent & $29.5 \#$ & (28) & 31.4 & $(22)$ & 24.0 & (6) & 0.484 & 0.072 \\
\hline Exacerbation & 12.5 & (12) & 8.6 & (6) & 24.0 & (6) & $0.046^{*}$ & 0.205 \\
\hline \multicolumn{9}{|l|}{ Mode of onset } \\
\hline Acute sudden & $49.5 \#$ & $(47)$ & $55.7 \#$ & (39) & 32.0 & $(8)$ & $0.042 *$ & 0.209 \\
\hline Repetitive sudden & $34.7 \#$ & (33) & $30.0 \#$ & (21) & $48.0 \#$ & (12) & 0.105 & 0.166 \\
\hline Repetitive gradual & 15.8 & (15) & 14.3 & $(10)$ & 20.0 & (5) & 0.501 & 0.069 \\
\hline \multicolumn{9}{|l|}{ Body side } \\
\hline Right & $60.0 \#$ & (57) & $62.9 \#$ & (44) & 52.0 & (13) & 0.342 & 0.098 \\
\hline Left & 40.0 & (38) & 37.1 & $(26)$ & 48.0 & (12) & 0.342 & 0.098 \\
\hline \multicolumn{9}{|l|}{ Time Loss } \\
\hline 0 days & 7.4 & (7) & 1.4 & (1) & 24.0 & (6) & $0.001 *$ & 0.380 \\
\hline 1-3 days & 11.6 & (11) & 8.6 & (6) & 20.0 & (5) & 0.125 & 0.157 \\
\hline 4-7 days & 17.9 & (17) & 18.6 & (13) & 16.0 & (4) & 1.000 & 0.030 \\
\hline 8-21 days & 32.6 & (31) & 34.3 & (24) & 28.0 & (7) & 0.565 & 0.059 \\
\hline$>21$ days & 24.2 & (23) & 30.0 & (21) & 8.0 & (2) & 0.031 * & 0.226 \\
\hline All season & 6.3 & (6) & 7.1 & (5) & 4.0 & (1) & 1.000 & 0.057 \\
\hline
\end{tabular}

* Significant differences between male and female trail runners $(p<0.05)$; \# significant differences between characteristics $(p<0.05)$.

Table 3 showed that the most common injury was joint sprain $(43.2 \% ; p<0.001$; ES $=0.421)$, and tendinopathy $(18.9 \%)$. The $11.6 \%$ of non-specific injuries included $5.3 \%$ cases of periostitis in the tibialis and $6.3 \%$ in the knees, ankles, and feet as undefined. The analysis by sex also showed differences in the diagnosis for male and female runners. While 
in male runners the most notable diagnosis is a joint sprain $(48.6 \% ; p<0.001 ; \mathrm{ES}=0.464)$ followed by tendinopathy $(18.6 \%)$, injuries in female runners were more distributed among joint sprain $(28.0 \%)$, tendinopathy $(20.0 \%)$, muscle injury $(12.0 \%)$, laceration $(12.0 \%)$, and non-specific diagnoses (24.0\%).

Table 3. Diagnosis of injuries in male and female trail runners.

\begin{tabular}{|c|c|c|c|c|c|c|c|c|}
\hline & \multicolumn{2}{|c|}{$\begin{array}{c}\text { All } \\
(n=95)\end{array}$} & \multicolumn{2}{|c|}{$\begin{array}{c}\text { Male } \\
(n=70)\end{array}$} & \multicolumn{2}{|c|}{$\begin{array}{l}\text { Female } \\
(n=25)\end{array}$} & \multirow[t]{2}{*}{$p$} & \multirow{2}{*}{$\mathrm{ES}(\varphi)$} \\
\hline & $\%$ & (n) & $\%$ & (n) & $\%$ & $(n)$ & & \\
\hline Joint sprain & $43.2 \#$ & $(41)$ & $48.6 \#$ & $(34)$ & 28.0 & (7) & 0.074 & 0.183 \\
\hline Tendinopathy & $18.9 \#$ & (18) & $18.6 \#$ & (13) & 20.0 & (5) & 0.875 & 0.876 \\
\hline Muscle injury & 6.3 & (6) & 4.3 & (3) & 12.0 & (3) & 0.184 & 0.140 \\
\hline Muscle contusion & 5.3 & (5) & 7.1 & (5) & 0.0 & (0) & 0.321 & 0.141 \\
\hline Laceration & 4.2 & (4) & 1.4 & (1) & 12.0 & (3) & 0.055 & 0.232 \\
\hline Bone fracture & 4.2 & (4) & 5.7 & (4) & 0.0 & $(0)$ & 0.570 & 0.125 \\
\hline Joint dislocation & 4.2 & (4) & 4.3 & (3) & 4.0 & (1) & 1.000 & 0.006 \\
\hline Abrasion & 2.1 & (2) & 2.9 & (2) & 0.0 & $(0)$ & 1.000 & 0.088 \\
\hline Non-specific & 11.6 & (11) & 7.1 & (5) & 24.0 & (6) & 0.034 * & 0.232 \\
\hline
\end{tabular}

* Significant differences between male and female trail runners $(p<0.05)$; \# significant differences between diagnoses $(p<0.05)$.

Finally, it should be noted that 34 joint sprains out of 41 occurred in 35 male runners, which gives a $97.1 \%$ probability of sustaining a joint sprain. However, only 7 joint sprains were reported by 16 female runners, reducing the percentage to $43.8 \%$. From the analysis of body region and diagnosis, it should be noted that $95.1 \%$ of joint sprains were in the ankles, while the second most common injury, tendinopathy $(43.9 \%)$, was distributed between the knee, the ankles, and other body segments.

\section{Discussion}

This study aimed at analyzing the injury incidence in young trail runners according to the body regions, and the type, mode of onset, and moment of occurrence, both globally and disaggregated by sex. To the knowledge of the authors, this is the first study of this kind with young trail runners.

The results of this study showed that for $8.7 \pm 2.4 \mathrm{~h} /$ week of training, the percentage of injured runners is $88.2 \%$ vs. $11.8 \%$ of non-injured. Jayanthi et al. [35] analyzed the injury risk in 1190 young athletes, of which 822 had ever been injured, and concluded that those who spent a mean of $11.2 \pm 2.6 \mathrm{~h}$ /week had a higher injury risk $(69.1 \%)$ than those who spent $9.1 \pm 6.3 \mathrm{~h} /$ week $(30.9 \%)$. The disagreement in percentages might be because this study analyzed individual sports in general. However, the studies by Lysholm and Wiklander [36] on sprint, middle-distance, and long-distance runners and by Deus et al. [37] on long-distance runners, showed similar values to our study, with an accident rate of $65.0 \%$ and $62.5 \%$, respectively.

A recent study carried out by Viljoen et al. [38] with trail runners, indicated that the percentage of injured people per $1000 \mathrm{~h}$ of training was $49.5 \%$, which is not in line with the percentage of $88.2 \%$ obtained in our study. The reason can be found in that the study analyzed popular runners, who were older and performed tests of different distances $(38 \mathrm{~km}, 65 \mathrm{~km}$, and $100 \mathrm{~km}$ ) which made the way of training and race rhythms very different. In fact, the same research group concluded in another study [39] that the percentage of injured people was $67.1 \%$. The study of Johansson [40] with professional orienteering runners, a sport with similar characteristics to trail running in terms of conditions and terrain, showed an accident rate of $74.2 \%$. Therefore, as suggested by Ortín, Garcés, and Olmedilla [41], the increase in professionalization and the practice of sports have led to a rise in the number of injuries. The mean number of injuries in our study of $2.2 \pm 1.8$ per $1000 \mathrm{~h}$ of training is in line with Lysholm and Wiklander [36], who indicated 2.5 per $1000 \mathrm{~h}$ in long-distance runners, and Johansson [40], who reported 3 per $1000 \mathrm{~h}$ in orienteering 
runners. Conversely, a review work on injury rate in different types of runners reported between 7.7 and 17.8 occurrences per $1000 \mathrm{~h}$ [13]. In this review, most of the studies computed the hours based on the injuries suffered during competition, where the athletes risk the most, and consequently, with greater occurrence in terms of the ratio exposure time to injuries produced. Furthermore, it is suggested that the injury risk in runners is lower at ages between 18 and 30 years [42], so runners younger than 18 years may maintain or reduce this lower risk.

According to our study, most of the injuries (92\%) were in the lower body, which is in line with the current literature [43]. The body regions that registered the most occurrences were the ankles $(49.5 \%)$, the knees $(17.9 \%)$, the lower legs $(9.5 \%)$, and the thighs $(5.3 \%)$. These data differ from other studies such as Viljoen et al. [38], who concluded that most of the injuries in trail running occurred in the knees (26.5\%), ankles (21.6\%), and feet (16.7\%). This discrepancy might be due to the age and type of runners, as well as the distances studied, where the paces are lower and there is a tendency to risk less. In other studies with runners [36,44,45], most occurrences vary between knees, hamstrings, shins (tibialis), and the hip, but they are based on injuries suffered in different types of runners and modalities, being the sprint modalities the ones that report the most [46]. These studies were related to athletics modalities, where the terrain is quite stable, which affects the body region of occurrence. Another source of dissimilarity is that the race distance, short-, middle- or long-distance, influences the time of execution, the previous warm-up, or the stride length. Therefore, the data of these studies from races characterized by constant and maintained stride with equal impacts may not be entirely comparable with those obtained in the present study.

It is generally accepted that the main body area of injury in mountaineering is the ankle with $40 \%$, followed by the knee (10.7\%), the foot (7.9\%), and the lower leg $(7.4 \%)$ [47], which are in line with our results. Thus, the continuous variability of the terrain, together with the unevenness, favors the incidence of this type of injury over others more typical of repetitive cyclic movements in much more stable terrain. The same review study reported orienteering injuries, where the most affected area is the ankle $(29.8 \%)$, followed by the knee $(18.1 \%)$ and lower leg $(14.8 \%)$, percentages values in line with Johansson [40], who observed that injuries in orienteers were located in the ankle, lower leg (both 27.27\%) and knee $(25.77 \%)$. This would confirm that the terrain is of key importance in terms of the areas affected by injury, rather than the running movement.

Although the majority were directly related injuries and occurred more during training $(40.0 \%)$ versus in competition $(33.7 \%)$, if the time spent in both groups is considered, the percentage of injuries in competition is much higher than while training, indirect injuries, or not at all related with trail running. This has been widely reported in several studies produced during practice and competition in different sports [48-51], which concluded that the percentage of injury per $1000 \mathrm{~h}$ of competition is higher than that of injuries produced during training/warm-up. These same studies also suggested that this increase might be caused by a rise in intensity. The review on ultra-endurance runners conducted by Scheer and Krabak [28] also suggested that the body region, diagnosis, and rate of injuries differed between competition and training as well as between different ultra-endurance races. While the back, knee, and bone stress injuries are common during training, in short ultra-trail races $(65 \mathrm{~km})$, the incidence is higher and it mainly affects the foot (plantar fasciitis), ankle (ankle sprain), and knee. They also concluded that the main injured regions are the knee (patella femoral pain syndrome), and ankle in long continuous races. So, for the particular case of trail running, another reason can be greater exposure to risk when trying to maintain high intensities in unstable and varied terrain.

In line with the above, our study showed that most of the injuries are due to acute sudden onset (49.5\%), repetitive sudden onset (34.7\%), and repetitive gradual onset (15.8\%). Additionally, more than half of acute sudden onset injuries are to the ankle, while the second most affected area, the knee, is usually by repetitive sudden onset or repetitive gradual onset. During the competition, the body is subjected to greater demands and 
fatigue, which increases the injury risk [52]. However, the prevalence of acute sudden onset injuries may also be due to the risks athletes take in intensity sports [53]. Trail running is a sport characterized by inconstant and unstable support. Although trail runners have greater stability in the joints of the lower body [54]. The leg joints, especially the ankle, require constant adaptation to the terrain, which can lead to injury in situations of intensity. Age may also be a factor, as young people are generally more prone to risk-taking than adults, who think more about the future consequences [55]. Likewise, this youth could explain why $57.0 \%$ of the injuries are new, compared to $29.5 \%$ of recurrent and $12.5 \%$ of exacerbation injuries, since practicing the sport at a high level for less time may reduce the time of exposure to possible injuries. In another study on trail running [26], despite agreeing that the ankle is the most affected area, they differ in their origins, indicating that most are repetitive gradual onset.

The results of our study indicated that joint sprain was the most common injury with $43.2 \%$ of the total produced, followed by tendinopathy (18.9\%). Furthermore, $95.1 \%$ of joint sprains were in the ankles, while tendinopathy was mainly distributed between the knee and the ankle. The ankle is the first of the joint chain that must adapt to the different variations in the terrain and its properties to generate movement, so therefore, the one that receives the first impact [56]. For other modalities of running with steady surfaces, most are stress injuries, highlighting tendinopathy in different parts, as well as periostitis in the tibialis [36]. In mountaineering, most of the ankle injuries are bone fractures (65\%) followed by joint sprains (35\%) [47]. The reasons might be due to specific characteristics of mountaineering that are not found in trail running. First, the added weight of the backpack increases the load to be borne by the joints. Second, the ankle is usually protected by a rigid boot, which largely prevents joint sprains. Consequently, injuries are usually due to a fall at a certain height or some other cause that the boot is not able to prevent, which in turn might be increased by the backpack weight. Orienteering, a sport similar to trail running, reports percentages of ankle injuries comparable to our study [47].

The differences in incidence by sex indicated that the percentage of injury in female runners is lower than in male runners: $1.8 \pm 1.3$ and $2.3 \pm 1.9$ injuries every $1000 \mathrm{~h}$, respectively, as also observed in male vs. female runners of other modalities $[12,57,58]$. These studies conclude that males have a significantly higher risk of running-related injuries than females, particularly young male athletes ( $<40$ years). While navicular drop remained as the only significant injury predictor in female athletes, body mass index, confidence interval, or previous occurrences were associated with running-related injuries in male athletes [58]. The most affected body region for both sexes was the ankle, but while male runners reported $54.3 \%$ of the affected areas, female runners reduced this affection to $36.0 \%$. Although there were no differences at the moment at which they occurred, there were differences in the type of injuries sustained. While in male runners $55.7 \%$ were acute sudden onset, followed by repetitive sudden onset (30.0\%), the main cause in female runners was repetitive sudden onset, with $48.0 \%$, followed by acute sudden onset (32.0\%). It is also noteworthy that joint sprains predominated in male runners, while they are more evenly distributed in female runners. Surprisingly, the injuries suffered in the right leg are significantly greater than in the left $(62.9 \%$ vs. $37.1 \%)$ for male runners, while female runners showed an even distribution between both sides (52.0\% vs. $48.0 \%)$. No studies have been found justifying these differences, but they could be related to running and risk-taking differences between sexes. The higher acute sudden onset rate of male runners might be due to the assumption of more risks and personal exposure to possible injuries than female runners. It is generally accepted that male athletes are more prone to take unnecessary risks, while female athletes take risks according to the perceived cost-benefit ratio $[53,59,60]$. In addition, in young categories of train running, female runners showed differences in terms of fitness and participation concerning male runners, which would play a role in the way female runners face the competition and assume the possible risks of the race. 


\section{Conclusions}

Young trail runners showed a specific injury profile due to the uneven characteristics of the mountain terrain, most occurring in the ankle region. Contrary to the athletic running modalities, ankle sprains and tendinopathy were the most common injury, as it is also observed in mountaineering and orientation. Most of the injuries in trail running were reported as new, over recurrent, and exacerbation. Likewise, the injury rate is low compared to other running modalities. The youth of the athletes could explain such a trend since the existence of injuries increases the chances of suffering others again.

The risk of directly related injuries is larger than indirect injuries and not at all related to trail running, because of the greater exposure to risk when trying to maintain high intensities in uneven terrain. Regarding differences between sexes, male runners showed an increased injury risk to the right leg, as well as an acute sudden onset. However, female runners showed no differences in injuries by body side, and repetitive sudden onsets were the most frequent injuries.

\subsection{Limitations}

This study has some limitations. The injury incidence was computed with the total amount of hours of practice, without distinguishing between training and competition. A disaggregated analysis would have given information about the incidence of these activities with different physical and psychological demands. In addition, it was difficult to compare our results with the rest of the literature on injuries. Some studies include options not identified in the present study such as small lacerations or even diseases derived from competition. On the other hand, the concept of injury every $1000 \mathrm{~h}$ of sports practice has been calculated in various studies in an estimated way based on injuries in the competition period and their effects on runners. Such extrapolation makes it difficult to compare results between studies and might be a source of disagreement. Finally, the collection of injury data with a single questionnaire over the last two years might have created a recall bias, especially for minor injuries. In order to avoid missing occurrences due to memory, future epidemiological studies should keep an updated record of injuries with a prospective design.

\subsection{Practical Applications}

The present study shows the injury profile of young national trail runners. The results with regards to the prevalence, body side, origin, recovery time, and differences by sex provide guidelines to coaches and practitioners to prevent injuries from happening, either through specific training in these areas, preventive strategy, or through the awareness of young athletes. Coaches and practitioners should adapt their training to prevent this type of injury, performing exercises that improve both proprioception and strength of the ankles and knees (main joints involved). It would also be advisable to monitor the injuries and analyze the factors that may have influenced them or to assess at what point athletes should protect these joints, either by using functional bandages or other elements such as knee or ankle pads.

Author Contributions: Conceptualization, A.P.-T.; Formal analysis, L.F.S.-G. and A.P.-T.; Funding acquisition, J.M.J.-O.; Investigation, L.F.S.-G. and B.P.; Methodology, B.P.; Project administration, A.P.-T. and J.M.J.-O.; Resources, A.P.-T.; Validation, B.P. and J.M.J.-O.; Writing—original draft, L.F.S.-G. and B.P.; Writing-review and editing, L.F.S.-G. and J.M.J.-O. All authors have read and agreed to the published version of the manuscript.

Funding: This research received no external funding.

Institutional Review Board Statement: The study was conducted according to the guidelines of the Declaration of Helsinki and approved by the Ethics Committee of the University of Alicante (UA 2019-02-25). 
Informed Consent Statement: Informed consent was obtained from all subjects involved in the study. Written informed consent has been obtained from the patients to publish this paper.

Data Availability Statement: Data can be obtained through the corresponding author on reasonable request.

Conflicts of Interest: The authors declare no conflict of interest.

\section{References}

1. Lee, D.C.; Brellenthin, A.G.; Thompson, P.D.; Sui, X.; Lee, I.M.; Lavie, C.J. Running as a key lifestyle medicine for longevity. Prog. Cardiovasc. Dis. 2017, 60, 45-55. [CrossRef] [PubMed]

2. Romaratezabala, E.; Castillo, D.; Raya-González, J.; Rodríguez-Negro, J.; Aritzeta, I.; Yanci, J. Health and wellness status perception of half-marathon runners: Influence of age, sex, injury, and training with qualified staff. Int. J. Environ. Res. Public Health 2020, 17, 5649. [CrossRef] [PubMed]

3. Pryor, A.; Carpenter, C.; Townsend, M. Outdoor education and bush adventure therapy: A socio-ecological approach to health and wellbeing. J. Outdoor Environ. Educ. 2005, 9, 3-13. [CrossRef]

4. Wolf, I.D.; Wohlfart, T. Walking, hiking and running in parks: A multidisciplinary assessment of health and well-being benefits. Landsc. Urban Plan. 2014, 130, 89-103. [CrossRef]

5. Farias-Torbidoni, E.I.; Seguí Urbaneja, J.; Ferrer, R.; Dorado, V. Carreras de trail running y marchas por montaña en España Número, evolución e incidencia sobre la Red Natura 2000 [Trail running races and mountain walks in Spain. Number, evolution and incidence on the Natura 2000 Network]. Pirineos 2018, 173, 034. [CrossRef]

6. Seguí, J.; Farias-Tobidoni, E.I. Trail running in Spain. Origin, evolution and current situation; natural areas. Retos 2018, 33, 123-128.

7. Eichenberger, E.; Knechtle, B.; Rüst, C.A.; Rosemann, T.; Lepers, R. Age and sex interactions in mountain ultramarathon running: The Swiss Alpine Marathon. Open Access J. Sports Med. 2012, 3, 73-80. [CrossRef]

8. Hoffman, M. Ultramarathon trail running comparison of performance-matched men and women. Med. Sci. Sports Exerc. 2008, 40, 1681-1686. [CrossRef]

9. Rowlands, D.S.; Pearce, E.; Aboud, A.; Gillen, J.B.; Gibala, M.J.; Donato, S.; Waddington, J.M.; Green, J.G.; Tarnopolsky, M.A. Oxidative stress, inflammation, and muscle soreness in an 894-km relay trail run. Eur. J. Appl. Physiol. 2012, 112, 1839-1848. [CrossRef]

10. Wegelin, J.A.; Hoffman, M.D. Variables associated with odds of finishing and finish time in a 161-km ultramarathon. Eur. J. Appl. Physiol. 2011, 111, 145-153. [CrossRef]

11. Lopes, A.D.; Hespanhol, L.C.; Yeung, S.S.; Costa, L.O.P. What are the main running-related musculoskeletal injuries? Sports Med. 2012, 42, 891-905. [CrossRef] [PubMed]

12. van der Worp, M.P.; ten Haaf, D.S.M.; van Cingel, R.; de Wijer, A.; Nijhuis-van der Sanden, M.W.G.; Staal, J.B. Injuries in runners: A systematic review on risk factors and sex differences. PLoS ONE 2015, 10, e0114937. [CrossRef] [PubMed]

13. Videbaek, S.; Bueno, A.M.; Nielsen, R.O.; Rasmussen, S. Incidence of running-related injuries per $1000 \mathrm{~h}$ of running in different types of runners: A systematic review and meta-analysis. Sports Med. 2015, 45, 1017-1026. [CrossRef] [PubMed]

14. Bahr, R.; Clarsen, B.; Derman, W.; Dvorak, J.; Emery, C.A.; Finch, C.F.; Hägglund, M.; Junge, A.; Kemp, S.; Khan, K.M.; et al. International Olympic Committee Consensus Statement: Methods for Recording and Reporting of Epidemiological Data on Injury and Illness in Sports 2020 (Including the STROBE Extension for Sports Injury and Illness Surveillance (STROBE-SIIS)). Orthop. J. Sports Med. 2020, 8, 232596712090290. [CrossRef] [PubMed]

15. Vernillo, G.; Giandolini, M.; Edwards, W.B.; Morin, J.B.; Samozino, P.; Horvais, N.; Millet, G.Y. Biomechanics and physiology of uphill and downhill running. Sports Med. 2017, 47, 615-629. [CrossRef] [PubMed]

16. Millet, G.Y.; Tomazin, K.; Verges, S.; Vincent, C.; Bonnefoy, R.; Boisson, R.C.; Gergelé, L.; Féasson, L.; Martin, V. Neuromuscular consequences of an extreme mountain ultra-marathon. PLoS ONE 2011, 6, e17059. [CrossRef]

17. Vernillo, G.; Savoldelli, A.; Zignoli, A.; Skafidas, S.; Fornasiero, A.; La Torre, A.; Bortolan, L.; Pellegrini, B.; Schena, F. Energy cost and kinematics of level, uphill and downhill running: Fatigue-induced changes after a mountain ultramarathon. J. Sports Sci. 2015, 33, 1998-2005. [CrossRef]

18. Morin, J.B.; Tomazin, K.; Edouard, P.; Millet, G.Y. Changes in running mechanics and spring-mass behavior induced by a mountain ultra-marathon race. J. Biomech. 2011, 44, 1104-1107. [CrossRef]

19. Vernillo, G.; Brighenti, A.; Limonta, E.; Trabucchi, P.; Malatesta, D.; Millet, G.P.; Schena, F. Effects of ultratrail running on skeletal-muscle oxygenation dynamics. Int. J. Sports Physiol. Perform. 2017, 12, 496-504. [CrossRef]

20. Vernillo, G.; Aguiar, M.; Savoldelli, A.; Martinez, A.; Giandolini, M.; Horvais, N.; Edwards, W.B.; Millet, G.Y. Regular changes in foot strike pattern during prolonged downhill running do not influence neuromuscular, energetics, or biomechanical parameters. Eur. J. Sport Sci. 2019, 20, 495-504. [CrossRef]

21. Latorre, P.A. Análisis de los Parámetros Biomecánicos de la Economía de Carrera en Atletas de Fondo a Velocidades Competitivas [Analysis of the Biomechanical Parameters of the Running Economy in Long-Distance Athletes at Competitive Speeds]. Master's Thesis, University of Jaen, Jaen, Spain, 2003. 
22. Santos-Concejero, J.; Tam, N.; Granados, C.; Irazusta, J.; Bidaurrazaga-Letona, I.; Zabala-Lili, J.; Gil, S.M. Interaction effects of stride angle and strike pattern on running economy. Int. J. Sports Med. 2014, 35, 1118-1123. [CrossRef] [PubMed]

23. Lieberman, D.E.; Warrener, A.G.; Wang, J.; Castillo, E.R. Effects of stride frequency and foot position at landing on braking force, hip torque, impact peak force and the metabolic cost of running in humans. J. Exp. Biol. 2015, 218, 3406-3414. [CrossRef]

24. Viljoen, C.T.; Janse van Rensburg, D.C.; Verhagen, E.; van Mechelen, W.; Tomás, R.; Schoeman, M.; Scheepers, S.; Korkie, E. Epidemiology of injury and illness among trail runners: A systematic review. Sports Med. 2021, 51, 917-943. [CrossRef] [PubMed]

25. Vernillo, G.; Savoldelli, A.; La Torre, A.; Skafidas, S.; Bortolan, L.; Schena, F. Injury and illness rates during ultratrail running. Int. J. Sports Med. 2016, 37, 565-569. [CrossRef] [PubMed]

26. Hespanhol Junior, L.C.; van Mechelen, W.; Verhagen, E. Health and economic burden of running-related injuries in Dutch trailrunners: A prospective cohort study. Sports Med. 2017, 47, 367-377. [CrossRef] [PubMed]

27. Babí, J.; Inglés, E.; Cumellas, L.; Farías, E.I.; Seguí, J.; Labrador, V. Runner's profile and propensity to sports injury. Rev. Int. Med. y Ciencias la Act. Física y del Deport. 2018, 18, 737-752. [CrossRef]

28. Scheer, V.; Krabak, B.J. Musculoskeletal injuries in ultra-endurance running: A scoping review. Front. Physiol. 2021, 12, 664071. [CrossRef]

29. Galvez, W.; Campos, C.; Chacon, Y. Epidemiology of injuries in students of Human Movement Sciences at the University of Costa Rica. Retos 2017, 31, 171-175.

30. Penichet-Tomás, A.; Jiménez-Olmedo, J.M.; Saiz-Colomina, S.; Jove-Tossi, M.; Martínez-Carbonell, J.A.; Silvestre-García, M. Incidence injury analysis on rowers in the Spanish Mediterranean Fixed Bench Championship 2012. J. Hum. Sport Exerc. 2012, 7 , 648-657. [CrossRef]

31. Eloranta, I.; Tittonen, T. The Reliability and Validity of Sport Injury Questionnaire in Questions Concerning Acute and Overused Injuries. Master's Thesis, University of Jyväskylä, Jyväskylän yliopisto, Finland, 2006.

32. Fuller, C.W.; Ekstrand, J.; Junge, A.; Andersen, T.E.; Bahr, R.; Dvorak, J.; Hägglund, M.; McCrory, P.; Meeuwisse, W.H. Consensus statement on injury definitions and data collection procedures in studies of football (soccer) injuries. Br. J. Sports Med. 2006, 40, 193-201. [CrossRef]

33. Cohen, J. Statistical Power Analysis for the Behavioral Sciences, 2nd ed.; Erlbaum: Hillsdale, NJ, USA, 1988.

34. Kotrlik, J.W.; Williams, H.A.; Jabor, M.K. Reporting and interpreting effect size in quantitative agricultural education research. J. Agric. Educ. 2011, 52, 132-142. [CrossRef]

35. Jayanthi, N.A.; LaBella, C.R.; Fischer, D.; Pasulka, J.; Dugas, L.R. Sports-specialized intensive training and the risk of injury in young athletes. Am. J. Sports Med. 2015, 43, 794-801. [CrossRef] [PubMed]

36. Lysholm, J.; Wiklander, J. Injuries in runners. Am. J. Sports Med. 1987, 15, 168-171. [CrossRef] [PubMed]

37. Deus, L.A.; Sousa, C.V.; Rosa, T.S.; Filho, J.M.S.; Santos, P.A.; Barbosa, L.D.; Silva Aguiar, S.; Souza, L.H.R.; Simões, H.G. Heart rate variability in middle-aged sprint and endurance athletes. Physiol. Behav. 2019, 205, 39-43. [CrossRef] [PubMed]

38. Viljoen, C.T.; Janse van Rensburg, D.C.C.; Jansen van Rensburg, A.; Booysen, E.; Chauke, S.; Coetzee, P.; Hurlimann, A.; Jooste, M.; Nibe, Y.; Schulenburg, C.; et al. One in four trail running race entrants sustained an injury in the 12 months training preceding the 2019 SkyRun race. Phys. Ther. Sport 2021, 47, 120-126. [CrossRef]

39. Viljoen, C.T.; van Rensburg, D.C.J.; Verhagen, E.; van Mechelen, W.; Korkie, E.; Botha, T. Epidemiology, clinical characteristics, and risk factors for running-related injuries among South African trail runners. Int. J. Environ. Res. Public Health 2021, 18, 12620. [CrossRef]

40. Johansson, C. Injuries in elite orienteers. Am. J. Sports Med. 1986, 14, 410-415. [CrossRef]

41. Ortín, F.J.; Garcés, E.J.; Olmedilla, A. Influencia de los factores psicológicos en las lesiones deportivas [Influence of psychological factors in sports injuries]. Papeles del Psicólogo 2010, 31, 281-288.

42. Nielsen, R.O.; Buist, I.; Parner, E.T.; Nohr, E.A.; Sørensen, H.; Lind, M.; Rasmussen, S. Predictors of running-related injuries among 930 novice runners: A 1-year prospective follow-up study. Orthop. J. Sports Med. 2013, 1, 1-7. [CrossRef]

43. Viljoen, C.T.; Sewry, N.; Schwellnus, M.P.; Janse Van Rensburg, D.C.; Swanevelder, S.; Jordaan, E. Independent risk factors predicting gradual onset injury in 2824 Trail Running Race Entrants: SAFER XVIII Study. Wilderness Environ. Med. 2021, 32, 293-301. [CrossRef]

44. Kluitenberg, B.; Van Middelkoop, M.; Diercks, R.; Van Der Worp, H. What are the differences in injury proportions between different populations of runners? A systematic review and meta-analysis. Sports Med. 2015, 45, 1143-1161. [CrossRef] [PubMed]

45. D'Souza, D. Track and field athletics injuries-a one-year survey. Br. J. Sports Med. 1994, 28, 197-202. [CrossRef] [PubMed]

46. Edouard, P.; Navarro, L.; Branco, P.; Gremeaux, V.; Timpka, T.; Junge, A. Injury frequency and characteristics (location, type, cause and severity) differed significantly among athletics ('track and field') disciplines during 14 international championships (2007-2018): Implications for medical service planning. Br. J. Sports Med. 2020, 54, 159-167. [CrossRef] [PubMed]

47. Fong, D.T.; Hong, Y.; Chan, L.; Yung, P.S.; Chan, K. A systematic review on ankle injury and ankle sprain in sports. Sport. Med. 2007, 31, 73-94. [CrossRef] [PubMed]

48. Rechel, J.A.; Yard, E.E.; Comstock, R.D. An epidemiologic comparison of high school sports injuries sustained in practice and competition. J. Athl. Train. 2008, 43, 197-204. [CrossRef] [PubMed]

49. Yard, E.E.; Collins, C.L.; Comstock, R.D. A comparison of high school sports injury surveillance data reporting by certified athletic trainers and coaches. J. Athl. Train. 2009, 44, 645-652. [CrossRef] 
50. Comstock, R.D. NFHS Injury Surveillance System. The National High School Sports Related Injury Surveillance Study: High School RIO TM High School Sports Participation Background; Research Institute at Nationwide Children's Hospital: Columbus, OH, USA, 2015.

51. Kerr, Z.Y.; Marshall, S.W.; Dompier, T.P.; Corlette, J.; Klossner, D.A.; Gilchrist, J. College Sports-Related Injuries-United States, 2009-2010 Through 2013-14 Academic Years. MMWR. Morb. Mortal. Wkly. Rep. 2015, 64, 1330-1336. [CrossRef]

52. Riazati, S.; Caplan, N.; Matabuena, M.; Hayes, P.R. Fatigue induced changes in muscle strength and gait following two different intensity, energy expenditure matched runs. Front. Bioeng. Biotechnol. 2020, 8, 360. [CrossRef]

53. Brymer, E. Risk taking in extreme sports: A phenomenological perspective. Ann. Leis. Res. 2010, 13, 218-238. [CrossRef]

54. Bean, R. Trail Runners: Neuromuscular and Biomechanical Insights. Master's Thesis, University of Cape Town, Cape Town, South Africa, 2018.

55. Karaman, N.G.; Çok, F. Adolescent risk-taking: Comparison between adolescents' and adults' opinion. Paid. (Ribeirão Preto) 2007, 17, 357-364. [CrossRef]

56. Voloshina, A.S.; Ferris, D.P. Biomechanics and energetics of running on uneven terrain. J. Exp. Biol. 2015, 218, 711-719. [CrossRef] [PubMed]

57. Macera, C.A.; Pate, R.R.; Powell, K.E.; Jackson, K.L.; Kendrick, J.S.; Craven, T.E. Predicting lower-extremity injuries among habitual runners. Arch. Intern. Med. 1989, 149, 2565-2568. [CrossRef] [PubMed]

58. Buist, I.; Bredeweg, S.W.; Lemmink, K.A.P.M.; Van Mechelen, W.; Diercks, R.L. Predictors of running-related injuries in novice runners enrolled in a systematic training program: A prospective cohort study. Am. J. Sports Med. 2010, 38, 273-280. [CrossRef]

59. Laurendeau, J. “Gendered risk regimes": A theoretical consideration of edgework and gender. Sociol. Sport J. 2008, 25, 293-309. [CrossRef]

60. Byrnes, J.P.; Miller, D.C.; Schafer, W.D. Gender differences in risk taking: A meta-analysis. Psychol. Bull. 1999, 125, 367-383. [CrossRef] 